\title{
ASSESSing The Color Image Differences DEPENDING ON THE REPRODUCTION DEVICE
}

\author{
Strgar KureciC, M; AgiC, D. \& MAndiC, L.
}

Abstract: This paper is dealing with a problem of managing and controlling color throughout the reproduction process. When color image is reproduced by different devices or on different media, its color appearance may vary quite a lot. This happens because different color reproduction media has different color gamuts, e.g. a range of colors they can reproduce. The purpose of this research was to identify the differences in color image reproduction when using CRT monitor and inkjet printer as the output reproduction devices. Color management techniques were used for achieving device independent color across different media used in the experiment. Procedure used for testing color reproductions was target-based, thus providing objective measurement and quantitative analysis of color.

Key words: color image reproduction, color management, color gamut, device characterization, device profile
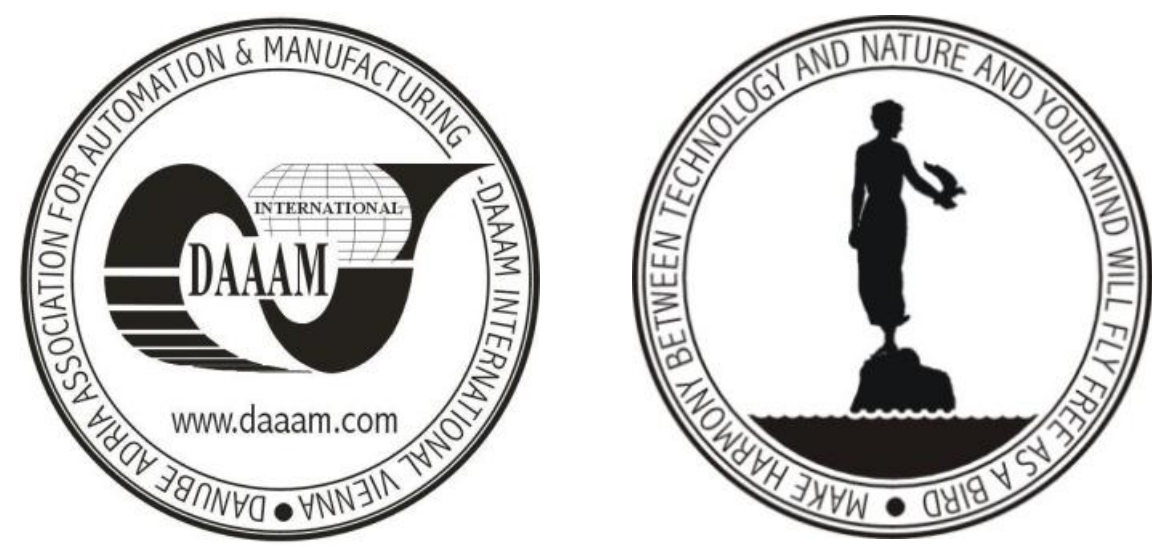

Authors' data: Dr.Sc. Strgar Kurecic, M[aja]; Univ.Prof. Agic, D[arko]; Dr.Sc. Mandic, L[idija], University of Zagreb Faculty of Graphic Arts, Getaldiceva 2, 10000 Zagreb, Croatia, mstrgar@grf.hr, darko.agic@grf.hr, lidija.mandic@grf.hr

This Publication has to be referred as: Strgar Kurecic, M[aja]; Agic, D[arko] \& Mandic, L[idija] (2010). Assessing the Color Image Differences Depending on the Reproduction Device, Chapter 08 in DAAAM International Scientific Book 2010, pp. 073-080, B. Katalinic (Ed.), Published by DAAAM International, ISBN 978-3901509-74-2, ISSN 1726-9687, Vienna, Austria

DOI: $10.2507 /$ daaam.scibook.2010.08 


\section{Introduction}

Digital color imaging is one of today's most exciting and fastest growing fields. At a first sight, it might seem that the endless flexibility by having signals in digital form should make all the problems easily solvable. The complexity of the situation arises from the different input and output media involved, and the different objectives required for different reproduction intents. It is often difficult or impossible to successfully exchange digital color images among different types of systems. The use of well-established measurement methods, along with color management applications and image file format standards, should allow the open interchange of digital images among systems (Green, 2010).

The reproduction of color images in an ever-widening array of media is challenging for a variety of reasons. That includes physical limitations of devices, colorimetric calibration and characterization of devices, viewing conditions, reproduction intent and preferences.

The aim of this research was to detect the differences in color image reproduction when using CRT monitor and inkjet printer as the output reproduction devices. It is important to point out that, in this study, monitor was not used as a softproof device (to simulate the appearance of a printed original). Equally as printer, monitor was used as a final reproduction device, with an aim to reproduce the original painting as accurate as possible.

\section{Background}

In the process of color image reproduction, one of the most important parameter is the gamut of the color reproduction media. Color reproduction media is term used for describing the media for capturing or displaying color information, e.g. a digital camera, scanner or a monitor. In printing, the color reproduction media is not the printer itself, but the combination of printer, colorants and substrate (Morovic \& Sun, 2002). According to the terminology used by CIE Technical Committee 8-03 on gamut mapping (http://www.colour.org/tc8-03), the color gamut is a range of colors achievable on a given color reproduction media under a given set of viewing conditions.

When discussing the color gamut it is very important to specify the corresponding viewing conditions and observer details. For example, printed image has a set of possible color gamuts, rather than a single one. Different levels of illumination result in different gamut volumes, illumination chromaticity changes gamut shape as well as volume. Viewing distance and flare in the environment also affect the color gamut (Morovic, 2003).

Another thing to consider is that some output devices are direct color reproduction media (like the monitors), while others (like printers) are not. As mentioned earlier, printers are not themselves color reproduction media, so it is not possible to talk about printer's gamut, if details about substrates, colorant, viewing conditions and observer are not specified. And, even then, it is more appropriate to talk about the color gamuts of prints, not printer. 
Practical implications of above given information's are when perform device characterization in the ICC color managed workflow. It is essential that each media is characterized under the individual combination of observer and viewing conditions for which the resultant device profile will be used. For example, characterizing a CRT monitor in a dark, flare-free environment, and then using it under typical office conditions is invalid and will result in substantial error.

Among the variety of devices, the gamut difference is most noticeable between a CRT monitor and a hardcopy printer. For a typical printer, the gamut volume in CIELAB color space is only 50 to $80 \%$ of that of a typical CRT monitor (Katoh, 1997). As shown in Fig. 1. a monitor's gamut is wider particularly in the green and blue regions and in the high lightness region. For this reason, it is impossible for the printer to reproduce all the colors achievable on the monitor. Consequently, out-ofgamut colors of the monitor have to be mapped to the inside of the printer gamut while minimizing a change in image appearance. The purpose of gamut mapping is to preserve the appearance of an image as much as possible when the image is reproduced by a different device or in a different media (Fraser et al., 2005).

Beside output devices, a visual characteristic of image that is being reproduced also influences how an image will be reproduced by different gamut mapping algorithms.

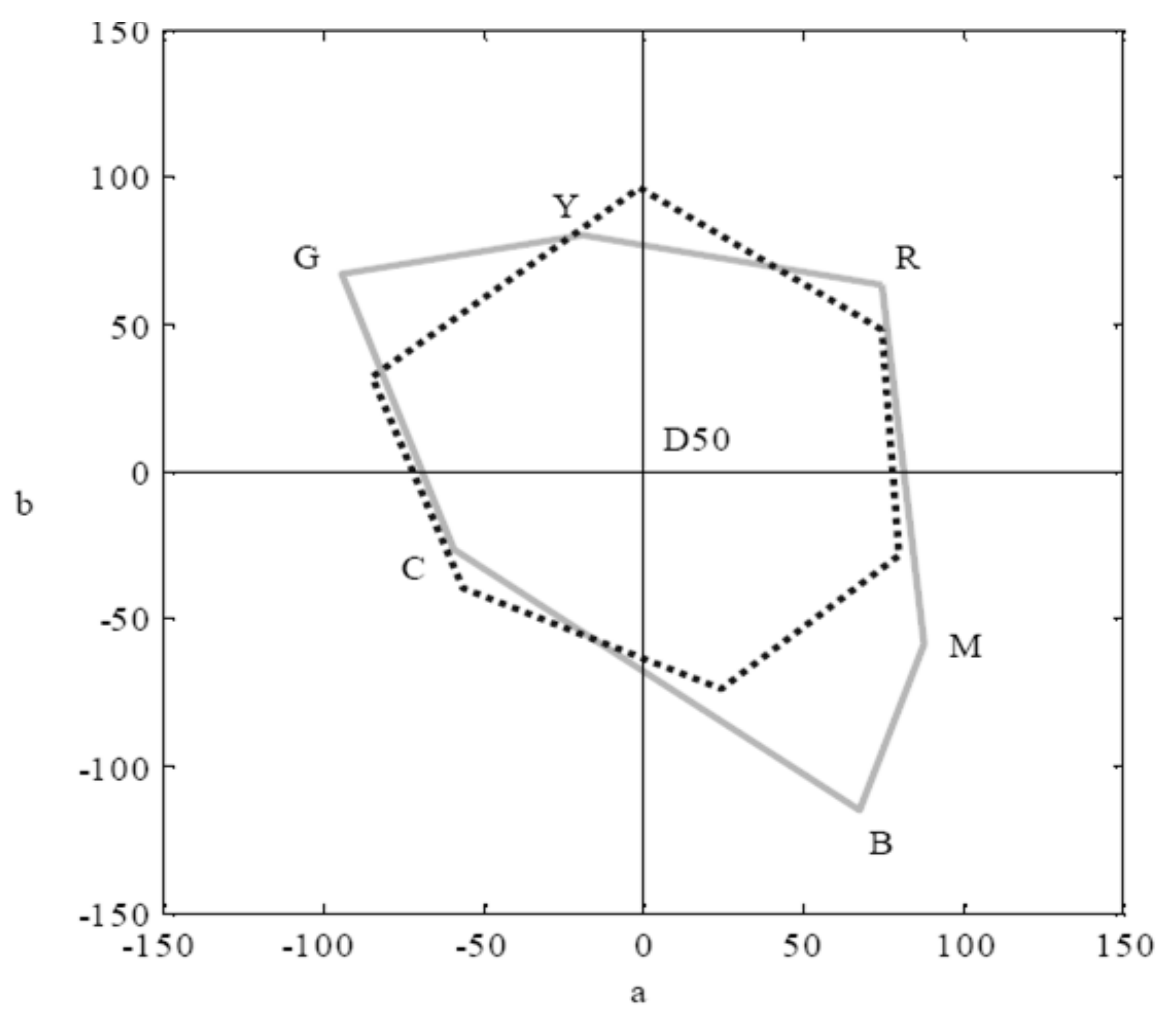

Fig. 1. Gamut of a typical CRT monitor and printer in CIELAB diagram

\section{Experimental}

In this experiment, the images (originals) intended for reproduction process were four gouache paintings. Chosen paintings have very different visual characteristics; their dominant colors, lightness range and saturation of used paints 
were different. Intention was to investigate the influence of specific visual characteristics of the original on the color reproduction. The color target used for digital camera characterization (GretagMacbethColorChecker) and the paintings were photographed in controlled studio conditions. Raw files (12 bits) from camera was converted in TIFF format and then supplied to the Profile maker software, which relates camera RGB signals to measured CIELAB values from target. Digital camera profile was made for light source used for imaging (daylight).

For color matching experiments the precise device characterization is essential. The output device used was cathode ray tube (CRT) monitor. The monitor was characterized by the method described in CIE Technical Report 122-1996, which is now adopted in many color management software. The basic colorimetric characterization of the CRT monitor can be represented as a combination of two parts: the tone reproduction curves (TRCs) for each channel, and the transformation matrix from linearized RGB to tristimulus values (XYZ). The TRCs denote the relationship between input digital count data and output luminance data for a given channel. The transformation matrix represents the color-additivity of emission from red, green and blue phosphors. The parameters necessary for the gamma-curve correction were derived from the eight ramp data of the primary colors (red, green, and blue), and the additive color mixture matrix was obtained by the regression technique (Draper, 1996). All the measurements were performed with GretagMacbeth Measure Tool and ProfileMaker software in darkened room.

Second output device used in this experiment was Epson Stylus PRO 4000 printer. Device was calibrated and characterized in the way to enable the largest gamut possible with given combination of paper and ink. Files coming to output device were in RGB mode, and were converted in CMYK with EFI Color Proof XF RIP. All reproductions used in evaluation were printed in the same day. Color reproduction media with specifications used in the experiment are listed in Tab. 1.

\begin{tabular}{|l|l|l|}
\hline $\begin{array}{l}\text { Color reproduction } \\
\text { media }\end{array}$ & Commercial name & Specifications \\
\hline Input device & $\begin{array}{l}\text { Nikon D70 digital camera with } \\
\text { AF Zoom-Nikkor 35-70mm, } \\
\text { f2.8D objective }\end{array}$ & $\begin{array}{l}\text { Used studio illumination: Dedolight } \\
\text { DLH 200S, daylight 5500K, 245 lux, } \\
\text { 3m distance from object }\end{array}$ \\
\hline Output device & $\begin{array}{l}\text { Mitsubishi Diamond PRO } \\
2070^{\mathrm{SB}} \text { CRT monitor }\end{array}$ & $\begin{array}{l}\text { White point: D50, Gamma: } 1.8, \\
\text { Lightness: } 100 \%\end{array}$ \\
\hline Output device & $\begin{array}{l}\text { Epson Stylus PRO 4000 } \\
\text { printer }\end{array}$ & $\begin{array}{l}\text { Pigment toner on EFI Gravure Proof } \\
\text { Paper 4245 semimatt, } 245 \mathrm{~g} / \mathrm{m}^{2}\end{array}$ \\
\hline
\end{tabular}

Tab. 1. Color reproduction media with specifications used in experiment

\section{Results and discussion}

For the purpose of objective measurement and quantitative analysis of color differences, CIELAB color space was used. It is currently the most important color space based on the opponent-color theory. 
The goal of the CIELAB color space design was to have perceptually uniform color differences throughout the space. $L^{*}$ represents lightness, $a^{*}$ approximates redness - greenness, $b^{*}$ approximates yellowness-blueness, $C^{*}{ }_{a b}$ approximates chroma and $h^{*}{ }_{a b}$ approximates hue. The chroma is varied as a parameter from the center to the edge of the circle, hue from $0^{\circ}$ to $360^{\circ}$, and lightness from 0 to 100.

Color differences are measured in the CIELAB space as the Euclidean distance between the coordinates for the two stimuli. We calculated color difference $\Delta \mathrm{E}_{94}$. The CIE94 has hue weighting function $S_{H}$ which is independent of hue angle. Equation is given (1).

$$
\Delta E_{94}=\sqrt{\left(\frac{\Delta L^{*}}{k_{L} S_{L}}\right)^{2}+\left(\frac{\Delta C_{a b}^{*}}{k_{C} S_{C}}\right)^{2}+\left(\frac{\Delta H_{a b}^{*}}{k_{H} S_{H}}\right)^{2}}
$$

where

$$
\begin{aligned}
& \mathrm{S}_{\mathrm{C}}=1+0,045 \mathrm{C}^{*}{ }_{\mathrm{ab}} \\
& \mathrm{S}_{\mathrm{H}}=1+0,015 \mathrm{C}^{*}{ }_{\mathrm{ab}} .
\end{aligned}
$$

On the basis of spectrophotometric measurements taken from monitor and from print, device gamuts were calculated and expressed in Color Cubic Units (CCU) for CIELAB color space, using ColorThink Pro application. The volume comparison of color gamut of used input and output devices is shown in Tab.2.

\begin{tabular}{|l|l|r|}
\cline { 2 - 3 } \multicolumn{1}{c|}{} & Device profile & Gamut volume \\
\hline Digital camera & CGRT24D.icc & 1.006 .260 \\
\hline Monitor & ICC monitor 0802.icc & 843.734 \\
\hline Printer & EPSON 4000.icc & 667.660 \\
\hline
\end{tabular}

Tab. 2. Volume comparison of color gamut of digital camera, monitor and print

To be able to quantitatively measure the color accuracy of reproductions, it was necessary to generate evaluation target for every painting, by choosing 24 different colored areas from digital image of painting. Those areas were measured with GretagMacbethSpectrolino spectrophotometer directly from original painting using mask with holes at exact coordinates, and compared with values of color samples (on evaluation target) measured from reproductions on monitor and reproductions on prints. Color difference $\left(\Delta E^{*}{ }_{94}\right)$ and differences in lightness $\left(\Delta L^{*}\right)$, chroma $\left(\Delta C^{*}{ }_{a b}\right)$ and tone $\left(\Delta H^{*}{ }_{a b}\right)$ for every original and reproduction were calculated and compared, shown in Tab. 3. A larger $\Delta E_{94}$ is indication that there is a more color variation. A negative $\Delta L$ and $\Delta C$ values indicate the reduction of lightness and chroma on reproduction.

To compare the colors of the original and colors of the reproductions, distribution of color samples from Painting 3 was plotted in CIELAB diagram, shown in Fig. 2. and Fig. 3. Paintings reproduced on monitor shows significantly smaller reduction of lightness and chroma then those reproduced on prints. Large errors in chroma are present mostly for orange, dark blue and green colors, which are out of 
Strgar Kurecic, M; Agic, D. \& Mandic, L.: Assessing the Color Image Differences ... printer gamut. Differences in tone are also larger for reproductions on prints. Overall best reproductions are those of Painting 1, which have low saturation and narrow lightness range, with uniformity of tone values.

\begin{tabular}{|l|r|r|r|r|r|r|r|r|}
\cline { 2 - 9 } \multicolumn{1}{c|}{} & \multicolumn{4}{c|}{ MONITOR } & \multicolumn{4}{c|}{ PRINTER } \\
\hline ORIGINAL & $\begin{array}{c}\Delta \boldsymbol{L}^{*} \\
\text { mean }\end{array}$ & $\begin{array}{c}\Delta \boldsymbol{C}^{*}{ }_{a b} \\
\text { mean }\end{array}$ & $\begin{array}{c}\Delta \boldsymbol{H}^{*}{ }_{a b} \\
\text { mean }\end{array}$ & $\begin{array}{c}\Delta \boldsymbol{E}^{*}{ }_{94} \\
\text { mean }\end{array}$ & $\begin{array}{c}\Delta \boldsymbol{L}^{*} \\
\text { mean }\end{array}$ & $\begin{array}{c}\Delta \boldsymbol{C}^{*}{ }_{a b} \\
\text { mean }\end{array}$ & $\begin{array}{c}\Delta \boldsymbol{H}^{*}{ }_{a b} \\
\text { mean }\end{array}$ & $\begin{array}{c}\Delta \boldsymbol{E}^{*}{ }_{94} \\
\text { mean }\end{array}$ \\
\hline Target & -0.12 & -0.51 & 2.70 & 3.59 & -0.85 & -4.71 & 2.68 & 4.81 \\
\hline Painting 1 & -0.12 & 1.07 & 2.21 & 3.23 & -0.58 & -2.30 & 2.71 & 3.99 \\
\hline Painting 2 & 0.04 & -2.02 & 2.90 & 4.71 & -1.72 & -3.23 & 4.49 & 6.79 \\
\hline Painting 3 & -1.94 & -4.92 & 2.94 & 4.53 & -4.59 & -9.82 & 3.86 & 7.65 \\
\hline Painting 4 & -0.62 & -2.80 & 2.41 & 3.24 & -1.71 & -6.75 & 3.37 & 5.88 \\
\hline $\begin{array}{l}\text { Final result } \\
\text { (average) }\end{array}$ & $\mathbf{- 0 . 5 5}$ & $\mathbf{- 1 . 8 4}$ & $\mathbf{2 . 6 3}$ & $\mathbf{3 . 8 6}$ & $\mathbf{- 1 . 8 9}$ & $\mathbf{- 5 . 3 6}$ & $\mathbf{3 . 4 2}$ & $\mathbf{5 . 8 2}$ \\
\hline
\end{tabular}

Tab. 3.Comparison of mean values for differences in lightness $\left(\Delta L^{*}\right)$, chroma $\left(\Delta C_{a b}^{*}\right)$,tone $\left(\Delta H^{*}{ }_{a b}\right)$ and color difference $\left(\Delta E^{*}{ }_{94}\right)$ for color reproductions on monitor and print

Total color differences obtained for samples reproduced on monitor are smaller than those obtained for reproductions made by printer. The reason for that is the fact that CRT monitor's gamut is larger than printer's gamut (Tab.2.), so as the possibility of color accurate reproduction, especially for very saturated colors. It is important to emphasize that those color differences obtained for reproductions made by printer would be even larger if the printer were used as hard proof for offset press. In that case, different device profile would be used (e.g. EuroscaleCoated.icc) with significantly smaller color gamut volume (375,318 CIELAB CCU).

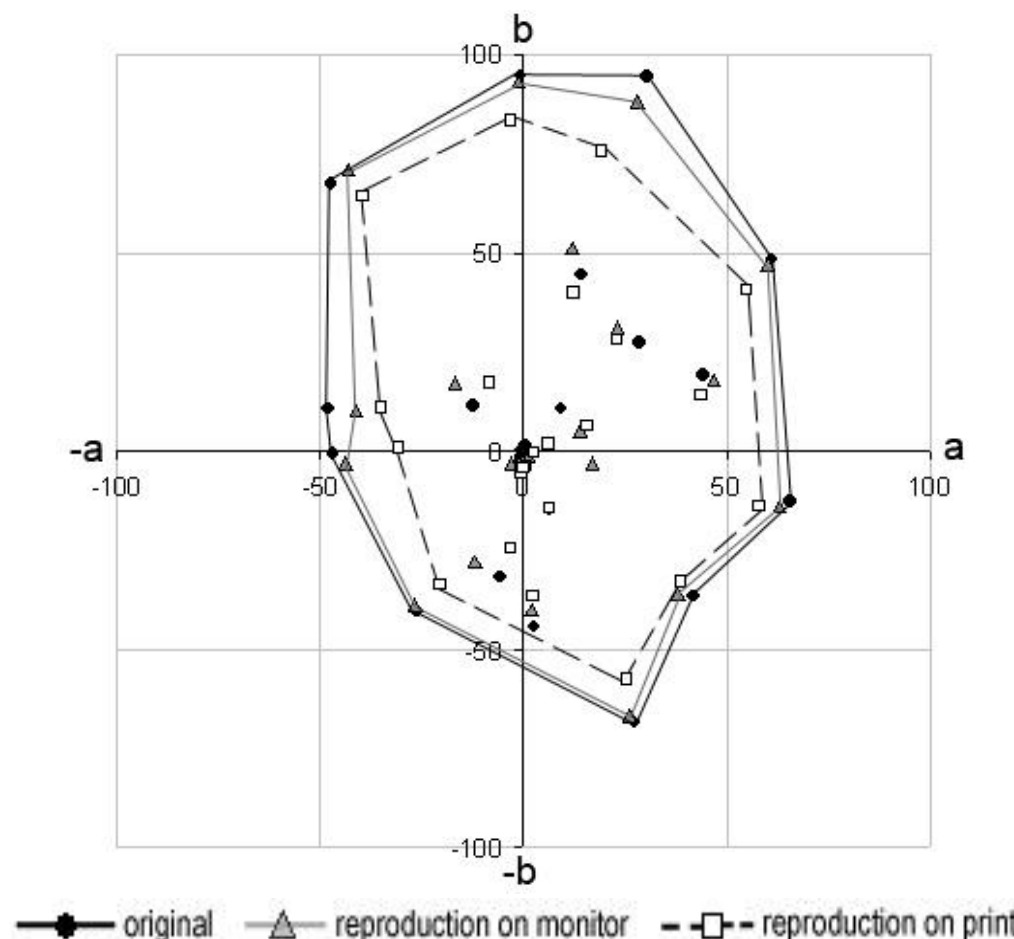

Fig. 2. Distribution of colors on original and on reproductions on monitor and print plotted in CIELAB $\mathrm{a}^{*} \mathrm{~b}^{*}$ diagram 

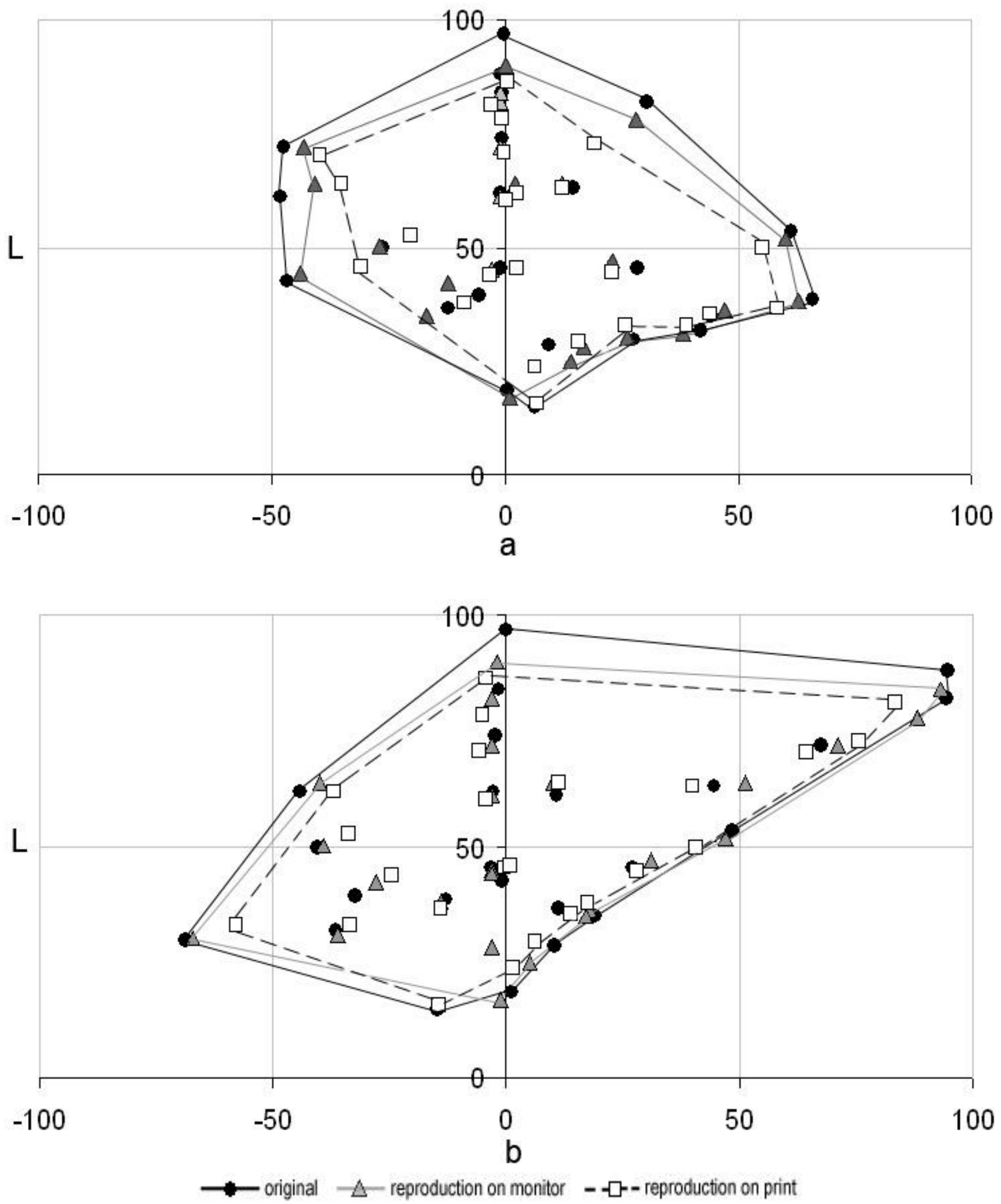

Fig. 3. Distribution of colors on original and on reproductions on monitor and print plotted in CIELAB L*a* diagram and CIELAB L*b* diagram

\section{Conclusion}

Observed color differences in image reproduction on CRT monitor and on print arise from the fundamental dissimilarities of those media. Monitor is self-luminance device, which produces color by mixing colored lights, using additive color mixing, 
while printer produce color by mixing of colorants, using subtractive color system on reflective substrate. Emissive devices like monitors attain their highest chroma at a relatively high lightness compared to the reflective media like prints. So, it is impossible to match output colors (on monitor or print) with original image colors exactly. There will always be some colors that are not reproducible by any output device. The quality of their reproduction will mostly depend on improved gamut mapping algorithms, which will be the subject of our future research. The next step will be to prove it with various reproduction systems.

\section{References}

Berns, R. S. (1996). Methods for Characterizing CRT Displays.Displays, Vol. 16, No. 4, (May 1996) pp. 173-182, ISSN 0141-9382

CIE 122-1996. (1996). The Relationship between Digital and Colorimetric Data for Computer Controlled CRT Displays

Draper, N. R. \& Smith, H. (1998). Applied Regression Analysis, John Wiley \& Sons, ISBN 0-471-17082-8, New York, USA

Fraser, B.; Murphy, C. \& Bunting, F. (2005).Real World Color Management,Peachpit Press, ISBN 0-321-26722-2, USA

Green, Phil. (2010). Color Management, John Wiley \& Sons Ltd, ISBN 078-0-47005825-1, United Kingdom

Katoh, N.;Deguchi T., \& Berns R. S. (2001). An Accurate Characterization of CRT Monitor (I) - Investigation of Past Studies and Clarifications of Gamma.Optical Review, Vol. 8, No. 5, (September 2001) pp. 305-314, ISSN 1340-6000

Katoh, N. (1997). Practical method for appearance match between soft copy and hard copy, Proceedings of SPIE, Walowit, E. (Ed.), pp. 170-181, SPIE Publication, Vol. 2170, ISBN 9780819414656, USA

MacDonald, L. W. \&Morovic J. (1995). Assessing the Effects of Gamut Compression in the Reproduction of Fine Art Paintings, Proceedings of 3rd IS\&T/SID Color Imaging Conference, pp. 194-200, ISBN0-89208-188-0, Scottsdale, Arizona November 1995, The Society for Imaging Science and Technology

MacDonald, L. W. (1996). Color Management and Display Calibration, Proceedings CIE Expert Symposium '96: Color Standards for Image Technology, pp. 63-69, UDC: 535.66, May 2006, Ottawa, Canada, National Research Council of Canada

Morovic, J \& Sun, P. (2002). How different are colorgamuts in cross-media color reproduction; Chapter 12 in Color Image Science, edited by MacDonald, L. W. \&Luo, M. R., John Wiley \& Sons Ltd, ISBN 0-471-49927-7, United Kingdom Morovic, J. (2003). Gamut mapping; Chapter 10 in Digital Color Imaging Handbook, edited by Sharma, G., CRC Press LLC, ISBN 0-8493-0900-X, USA *** (2004) http://www.colour.org/tc8-03, Gamut Mapping, Accessed on: 2009-11-19 